\title{
IgG antibodies against anaerobic bacteria in blood donor sera
}

\author{
ANNA SCHWAN \\ From the Institute of Clinical Bacteriology, Uppsala University, Uppsala, Sweden
}

SUMMARY Fifty-six blood donor sera were examined by indirect immunofluorescence for IgG antibodies to a selection of anaerobic bacterial strains, often isolated from wound cultures. Another 25 sera were examined for IgG antibodies to six NCTC Bacteroides strains. A wide range of IgG antibody titres were found against Fusobacterium, Clostridium, and anaerobic streptococcal species. Very low titres were found against the Bacteroides strains. It is suggested that the testing of a single serum specimen for IgG antibodies against a representative collection of Bacteroides fragilis strains could be helpful in verifying a clinical suspicion of infection with these organisms.

During the last decade several reports have appeared concerning the humoral immune response to anaerobic bacterial infections, due mainly to bacteroides, ${ }^{1-5}$ but also to fusobacteria, ${ }^{6}$ clostridia, ${ }^{16}$ and anaerobic cocci. ${ }^{7} 8$ Antibodies have been detected with tube agglutination, ${ }^{1-3}$ immunodiffusion, ${ }^{1346}$ and indirect immunofluorescence, ${ }^{1-35-8}$ as well as with other immune assays. ${ }^{25-7}$ However, relatively wide ranges of antibody titres have been demonstrated also in normal sera against species mentioned above. ${ }^{135-10}$ Particularly high titres have been found against some strains of Clostridium perfringens. ${ }^{811}$

The demonstration of an active immune response or, as has been proposed by some authors, ${ }^{12}$ strongly elevated titres in single serum specimens, especially when related to IgG antibodies, is of diagnostic significance when an anaerobic infection is suspected. Hofstad $^{13}$ suggested that because of the common occurrence of IgM antibodies to anaerobes in normal sera the demonstration of IgG antibodies would be more valuable when trying to detect an anaerobic infection by means of serology.

We have studied the occurrence of IgG antibodies in sera from healthy individuals against various anaerobic species, often associated with anaerobic infections.

\section{Material and methods}

BACTERIAL STRAINS

All strains were isolated from wound cultures unless otherwise stated. The following strains were in-

Accepted for publication 23 June 1980 cluded in the study: four strains of Fusobacterium nucleatum (one kindly provided by Dr A Krook, Central County Hospital, Örebro, Sweden), one strain (isolated from faeces) of $F$. naviforme (provided by Dr A Krook), three strains of Clostridium ramosum (two kindly provided by Mrs A Andersson, Central Hospital, Västerås, Sweden) one of which was an ATCC type strain (ATCC 25582), one strain each of $\mathrm{Cl}$. perfringens, Veillonella alcalescens, Peptococcus magnus, Peptostreptococcus anaerobius, three strains of $\boldsymbol{P}$. asaccharolyticus and four strains of $P$. prevotii, six strains of Bacteroides fragilis (five of these were NCTC strains, namely, 8560, 9343, 9344, 10581, and 10584), and one strain each of $B$. vulgatus and B. thetaiotaomicron (NCTC 10582).

The strains were grown on blood agar plates supplemented with haemin and vitamin $\mathrm{K}$ using the GasPak system (BBL, Cockeysville, Md, USA). They were identified according to the directions outlined by Holdeman et al. ${ }^{14}$ with the use of the API 20A and APIzym tests (API, Plainview, NY, USA).

\section{SERUM SPECIMENS}

Serum samples from healthy blood donors were obtained with the kind assistance of Dr J Säfwenberg and Dr A Danersund, The Blood Centre, University Hospital, Uppsala. One group of sera consisted of 56 specimens from 19 female blood donors (mean age 35 years, range 21-55) and 37 male donors (mean age 36 years, range 20-59). The other group consisted of 25 sera from 12 women (mean age 36 years, range 21-53) and 13 men (mean age 39, range 22-63). The sera were inactivated for 30 minutes at $56^{\circ} \mathrm{C}$. They were kept frozen at $-70^{\circ} \mathrm{C}$ until used. 
PREPARATION OF ANTIGENS

The bacteria were grown on solid media as described above and harvested in sterile $0.15 \mathrm{M}$ sodium chloride after 48 hours. The cells were washed three times and resuspended in phosphate-buffered saline

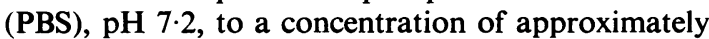
$10^{8}$ cells $/ \mathrm{ml}$. Glass slides with circular areas of $50.2 \mathrm{~mm}^{2}$ (Novakemi AB, Sweden) were used for smears. On each area $0.01 \mathrm{ml}$ bacterial suspension was smeared. The slides were air-dried and stored at $-20^{\circ} \mathrm{C}$ until used.

\section{INDIRECT IMMUNOFLUORESCENCE TESTS}

Heat-inactivated serum specimens were diluted 1:10 to $1: 1280$ in twofold increments in PBS containing $4 \%$ bovine serum albumin; $0.01 \mathrm{ml}$ of each dilution was allowed to react for 30 minutes with the bacteria on the slides, which were incubated in a moist chamber at $37^{\circ} \mathrm{C}$. After washing in PBS for 10 minutes $0.01 \mathrm{ml}$ of fluorescein-isothiocyanate (FITC)-labelled rabbit antihuman IgG (DAKO immunoglobulins, Copenhagen, Denmark), incubated at $37^{\circ} \mathrm{C}$ for 30 minutes, and washed with PBS as above. The conjugate had the molar F/P ratio of $2 \cdot 3$ and was diluted 1:10 in PBS. Various dilutions were checked and 1:10 gave optimal results. The slides were mounted under a cover glass with phosphate-buffered glycerin. The preparations were read under a Zeiss Standard 14 fluorescence microscope equipped with incident light using narrow blue band activation and an LP 520 as a secondary filter. The lamp was an Osram HBO 50 mercury lamp and the objective was a planapochromate $100 / 1 \cdot 25$. The criteria for recording the specific staining of the bacteria have been stated. ${ }^{8}$
Controls with smears stained only with the conjugate were always included.

\section{Results}

Antibody titres found in 56 blood donor sera against the 21 anaerobic strains representing various species are shown in Table 1.

Antibodies were found in most or all sera against three of the $F$. nucleatum strains, sometimes in high titres. Titres were much lower against the fourth strain, and 37 sera were negative. The $F$. naviforme strain reacted with half the sera in titres up to $1 / 40$ $1 / 80$.

Antibody titres of $1 / 20$ to $V$. alcalescens were found in one-third of the sera.

Titres against two of the $\mathrm{Cl}$. ramosum strains were sometimes quite high; a majority of the sera were positive $\geqslant 1 / 20$. Very few sera were positive for the third strain. Most sera gave very high titres against the $\mathrm{Cl}$. perfringens strain.

Most sera gave low titres against two $P$. asaccharolyticus strains, never exceeding 1/20. Most sera, however, had titres against the third strain, 25 of them as high as $1 / 1280$.

A majority of the sera were negative against two strains of $\boldsymbol{P}$. prevotii, while many sera were positive against the remaining two strains.

Most of the sera had titres $\leqslant 1 / 10$ against one strain of $P$. magnus, all gave titres $\geqslant 1 / 40$ with a strain of $P$. anaerobius, often in very high titres.

Antibody titres against a $B$. fragilis strain were very low, never exceeding $1 / 20$. The same was true for $B$. vulgatus, with titres of $1 / 40$ in only a few cases.

Table 1 Distribution of IgG antibody titres against 21 anaerobic bacterial strains in 56 blood donor sera

\begin{tabular}{|c|c|c|c|c|c|c|c|c|c|c|}
\hline \multicolumn{2}{|l|}{ Bacterial strain } & \multicolumn{9}{|c|}{ Reciprocal titre } \\
\hline & & $<10$ & 10 & 20 & 40 & 80 & 160 & 320 & 640 & 1280 \\
\hline F. nucleatum & 1886 & 10 & 17 & 14 & 7 & 3 & 2 & & 3 & \\
\hline F. nucleatum & 5068 & 37 & 13 & 6 & & & & & & \\
\hline F. nucleatum & 1858 & 10 & 23 & 8 & 6 & 3 & 3 & 1 & 1 & 1 \\
\hline F. nucleatum & 8317 & & 2 & 5 & 9 & 29 & 6 & 1 & 1 & 3 \\
\hline$F$. naviforme & & 28 & 15 & 9 & 3 & 1 & & & & \\
\hline V.alcalescens & & 23 & 13 & 5 & 11 & 4 & & & & \\
\hline Cl. ramosum ATCC & 25582 & 10 & 7 & 16 & 14 & 5 & 3 & 1 & & \\
\hline Cl. ramosum & $77-203$ & 17 & 16 & 17 & 1 & 4 & 1 & & & \\
\hline Cl. ramosum & & 51 & 4 & 1 & & & & & & \\
\hline Cl.perfringens & K6 & & & & & & & 1 & 2 & 53 \\
\hline P. asaccharolyticus & 3203 & 52 & 3 & 1 & & & & & & \\
\hline P. asaccharolyticus & 3463 & 54 & 2 & & & & & & & \\
\hline P. asaccharolyticus & 6480 & 11 & & 3 & 4 & 2 & 2 & 3 & 6 & 25 \\
\hline P. prevotii & & 40 & 7 & 7 & 2 & & & & & \\
\hline P. prevotii & 3569 & 49 & 6 & 1 & & & & & & \\
\hline$P$. prevotii & 3158 & 4 & 12 & 9 & 19 & 6 & & 3 & 3 & \\
\hline$P$.prevotii & 3147 & 27 & 17 & 7 & 3 & 1 & 1 & & & \\
\hline$P$. magnus & & 50 & 5 & 1 & & & & & & \\
\hline P. anaerobius & & & & & 1 & 3 & 4 & 1 & 4 & 43 \\
\hline B. fragilis & K5 & 41 & 10 & 5 & & & & & & \\
\hline B. vulgatus & K38 & 27 & 15 & 10 & 4 & & & & & \\
\hline
\end{tabular}


Because of the low titres found to the $B$. fragilis strain and the fact that $B$. fragilis is an important pathogen in anaerobic infections, the study was extended with another five $B$. fragilis strains, all of them NCTC strains, and 25 other blood donor sera. Since $B$. thetaiotaomicron has also been incriminated in anaerobic infections, an NCTC strain of this species was also included. The results are shown in Table 2. One of the strains (NCTC 9344) reacted with two sera with a titre of $1 / 40$. All remaining strains gave titres of $\leqslant 1 / 20$. Half or more of the sera were negative against all six strains.

There was no obvious correlation between antibody titres against the bacterial strains and the blood donors' sex, age, and blood group.

\section{Discussion}

The present study shows a considerable range of low as well as high IgG antibody titres in sera from healthy blood donors against a wide range of anaerobic bacterial species, most of which are incriminated in clinically significant anaerobic bacterial infections. The findings are in main agreement with those demonstrated by other investigators, some of whom reported on IgM and IgG antibodies against Bacteroides or Fusobacterium species. ${ }^{6} 10131516$ The IgG antibodies demonstrated in the present study in normal sera against these species as well as against Clostridium and anaerobic streptococcal species may have practical implications from serodiagnostic and other points of view and therefore deserve to be commented upon.

The demonstration of an increase of specific IgG antibodies against pathogenic microbial agents is axiomatic for the serodiagnosis of many infectious diseases and has been shown to be true for anaerobic bacterial infections also. ${ }^{1356}$ It presupposes the comparison of titres in acute and convalescent phase serum specimens. This situation rarely occurs in anaerobic infections, which are often longstanding. If a convalescent phase serum specimen only is examined the diagnostic value of an elevated antibody titre will therefore be dependent upon whether or not low titres generally occur in normal sera. The present study shows that these criteria will not be fulfilled for many of the Fusobacterium, Clostridium, and anaerobic streptococcal species. It is of interest to note, however, that the titres were generally low or very low against $B$. fragilis and a few other tested Bacteroides species.

Since $B$. fragilis is one of the more important pathogens in anaerobic bacterial infections and is usually resistant to penicillins and most cephalosporins, the findings of the present study have practical implications from a serodiagnostic point of view. By examining patients' sera against a battery of $B$. fragilis strains, known to occur often in clinical infections, a suspicion of bacteroides infection could be verified and allow rational use of antibiotics. The NCTC strains that were used in the present study were shown by Elhag and Tabaqchali17 to represent various serotypes. These strains could be the basis for a representative collection of $\boldsymbol{B}$. fragilis antigens in serodiagnostic tests.

Since there is no accepted serological classification for most anaerobic bacterial species the importance of selecting several strains in tests of this kind is obvious from the present study. The findings indicate that various serogroups or serotypes occur among $P$. asaccharolyticus, $P$. prevotii, $F$. nucleatum, and $\mathrm{Cl}$. ramosum strains.

The bacterial strains used in this study represent members of the normal anaerobic flora of the gastrointestinal, urogenital, and respiratory tracts as well as the oral cavity. The nature of the high IgG antibody titres against some of these is uncertain, as is its importance for the immune defence mechanisms. The antibodies might be the result of a stimulation of the immune system. They could, however, also represent cross-reacting antibodies. Serological similarities are known between $\mathrm{Cl}$. perfringens theta toxin and haemolysin from group A streptococci and pneumococci. ${ }^{18}$ Pseudoimmune reactions analogous to those between protein A of Staphylococcus aureus and the Fc pieces of the IgG molecule were excluded by absorption experiments. More investigations are therefore needed to elucidate the background and the importance of our findings and those of other investigators. ${ }^{81011}$

Table 2 Distribution of IgG antibody titres against Bacteroides in 25 blood donor sera

\begin{tabular}{|c|c|c|c|c|c|c|c|c|}
\hline \multirow[t]{2}{*}{ Bacterial strain } & & \multicolumn{7}{|c|}{ Reciprocal titre } \\
\hline & & $<10$ & 10 & 20 & 40 & 80 & 160 & 320 \\
\hline $\begin{array}{l}\text { B. fragilis } \\
\text { B. fragilis } \\
\text { B. fragilis } \\
\text { B. fragilis } \\
\text { B. fragilis } \\
\text { B. thetaiotaomicron }\end{array}$ & $\begin{array}{l}\text { NCTC } 8560 \\
\text { NCTC } 9343 \\
\text { NCTC } 9344 \\
\text { NCTC } 10581 \\
\text { NCTC } 10584 \\
\text { NCTC } 10582\end{array}$ & $\begin{array}{l}19 \\
19 \\
12 \\
19 \\
19 \\
18\end{array}$ & $\begin{array}{l}6 \\
3 \\
7 \\
4 \\
5 \\
7\end{array}$ & $\begin{array}{l}3 \\
4 \\
2 \\
1\end{array}$ & 2 & & & \\
\hline
\end{tabular}




\section{References}

1 Danielsson D, Lambe DW, Persson S. The immune response in a patient to an infection with Bacteroides fragilis ss fragilis and Clostridium difficile. Acta Pathol Microbiol Scand section B 1972;80:709-12.

2 Danielsson D, Kjellander J, Persson S, Wallensten S. Investigation of the immune response to aerobic and anaerobic intestinal bacteria in a patient with Crohn's disease. Scand J Infect Dis 1979; suppl. 19:52-60.

3 Lambe DW, Danielsson D, Vroon DH, Carver RK. Immune response in eight patients infected with Bacteroides fragilis. J Infect Dis $1975 ; 131$ :499-508.

4 Rissing JP, Crowder JG, Smith JW, White A. Detection of Bacteroides fragilis infection by precipitin antibody. $J$ Infect Dis $1974 ; 130: 70-3$.

${ }^{5}$ Schwan A, Rydén A-C. Antibody response in thirteen patients with Bacteroides fragilis infections. Scand $J$ Infect Dis 1978;10:213-8.

- Danielsson D, Lambe DW, Persson S. Immune response to anaerobic infections. In: Balows A, Dehaan RM, Dowell VR, Guze LB, eds. Anaerobic bacteria. Role in disease. Springfield, Ill: Charles C Thomas, 1974;173-91.

7 Taylor AG, Fincham WJ, Golding MA, Cook J. Infection of total hip prostheses by Peptococcus magnus: an immunofluorescence and ELISA study of two cases. J Clin Pathol 1979;32:61-5.

B Schwan A, Rydèn A-C. The clinical importance of anaerobic bacteria in wound infections after gastrointestinal surgery. Scand J Infect Dis 1978;10:119-25.

- Persson S, Danielsson D. On the occurrence of serum antibodies to Bacteroides fragilis and serogroups of $E$. coli in patients with Crohn's disease. Scand J Infect Dis 1979;suppl. $19: 61-7$.

${ }^{10}$ Kristoffersen T. Immunochemical studies of oral Fusobacteria. 6. Distribution of a group reactive antigen among some bacteria and occurrence of antibodies in human sera to this antigen. Acta Pathol Microbiol Scand 1969;77:717-26.

11 Danielsson D. Personal communication.

${ }^{12}$ Rissing JP, Buxton TB, Edmondson HT. Detection of specific IgG antibody in sera from patients infected with Bacteroides fragilis by enzyme-linked immunosorbent assay. J Infect Dis 1979;140:994-8.

${ }^{13}$ Hofstad T. Antibodies reacting with lipopolysaccharides from Bacteroides melaninogenicus, Bacteroides fragilis, and Fusobacterium nucleatum in serum from normal subjects. J Infect Dis 1974;129:349-52.

14 Holdeman LV, Cato EP, Moore WEC. Anaerobe laboratory manual. Blacksburg, Va: Virginia Polytechnic Institute and State University, 1977.

${ }^{15}$ Quick JD, Goldberg HS, Sonnenwirth AC. Human antibody to Bacteroidaceae. Am J Clin Nutr 1972;25:1351-6.

16 Evans RT, Spaeth S, Mergenhagen SE. Bactericidal antibody in mammalian serum to obligatory anaerobic gram negative bacteria. J Immunol 1966;97:112-9.

${ }^{17}$ Elhag KM, Tabaqchali S. The distribution of Bacteroides fragilis serotypes amongst clinical strains. J Hyg Camb $1978 ; 81: 89-97$.

${ }^{18}$ Smith LD. The pathogenic anaerobic bacteria. Springfield, Ill: Charles C Thomas, 1975;153.

Requests for reprints to: Dr Anna Schwan, Institute of Clinical Bacteriology, Uppsala University, Uppsala, Sweden. 